\title{
Laser Tattoo Removal
}

\author{
Eric F. Bernstein, M.D. ${ }^{1}$
}

\section{ABSTRACT}

Tattooing has been a part of human culture since the earliest beginnings of modern civilization. What has changed over the millennia are the myriad of colors with which we can now express our thoughts, feelings, and desires through body art. What has not changed is human nature, and our propensity to change our minds about what it is we think, feel, and wish to express on the canvas of our skin. Our fickle nature results in the desire to change what has been placed as a permanent reminder of a friend, spouse, or as a work of art. The technology used to remove tattoos began with destructive methods of removal, which wreaked havoc not only on the tattoo but more prominently on the skin containing that tattoo. The discovery of selective photothermolysis, the ability to selectively remove target structures without disrupting the surrounding skin, made it at least possible to remove tattoos without destroying the surrounding skin and leaving a scar. Theory predicted that pulse durations in the nanosecond domain would be optimal for tattoo removal, and the Q-switched neodymium:yttrium-aluminum-garnet, alexandrite, and ruby lasers operate in this range and are the key tools for modern tattoo removal. Too often, the wrong devices operating in the millisecond range, such as intense pulsed light sources, or lasers that are nonselective, such as the carbon dioxide laser, are used to treat tattoos, resulting in significant scarring without complete removal of the tattoo. Although the Q-switched lasers are capable of removing tattoos without harming the skin, removal often takes numerous treatments and still can be incomplete, especially when attempting to remove multicolored tattoos. Developments leading to removable tattoo inks, feedback systems to detect the absorbance characteristics of tattoo inks, dermal clearing agents, and perhaps even shorter pulse-duration lasers should result in improvements in tattoo removal in the near future.

KEYWORDS: Laser, tattoo, pigment, skin, Q-switched, ruby, alexandrite, Nd:YAG

\section{HISTORY OF TATTOOING}

The art of body decoration has been in existence since the early beginnings of our modern civilization. Recently, many examples of tattooing have been found on mummies from different parts of the world, as well as on the body of a man recently found frozen in the mountains on the border of modern-day Italy and Austria. The Bronze Age hunter who was found frozen in a glacier and extremely well preserved had numerous tattoos present on his body, and these had remained throughout the thousands of years he stayed frozen. ${ }^{1}$ Tattooing was practiced by nearly all of the cultures that inhabited the Pacific Islands and is thought to predate the settlement of Polynesia. Its origins are thought to go back to the initial migration and colonization of the Pacific, where people from Southeast Asia migrated eastward and colonized numerous islands throughout their travels east. These sea voyagers practiced tattooing

\footnotetext{
${ }^{1}$ Department of Dermatology, University of Pennsylvania, Philadelphia, Pennsylvania.

Address for correspondence and reprint requests: Eric F. Bernstein, M.D., Laser Surgery \& Cosmetic Dermatology Centers, Inc., 931 Haverford Road, 2nd Floor, Bryn Mawr, PA 19010.
}

Lasers in Plastic Surgery; Guest Editor, Ramsey F. Markus, M.D. Semin Plast Surg 2007;21:175-192. Copyright (C) 2007 by Thieme Medical Publishers, Inc., 333 Seventh Avenue, New York, NY 10001, USA. Tel: +1(212) 584-4662.

DOI 10.1055/s-2007-991186. ISSN 1535-2188. 
and decoration of a pottery type called Lapita, using needles to decorate pottery with a leathery consistency. ${ }^{2}$ Tools and instruments used for tattooing, which included needles and pigment reservoirs, have been found dating back to Upper Paleolithic time periods, which ranged from $38,000 \mathrm{BC}$ to $10,000 \mathrm{BC}$. Numerous figurines depicting tattooing on their bodies have been discovered from up to 4000 years ago. ${ }^{3}$ A particularly well-preserved mummy dating back $\sim 4000$ years ago demonstrated intact tattoos. Many artifacts that have been discovered from this era show markings resembling the tattoos on this mummy. Thus, tattooing was probably widespread many thousands of years ago and even earlier. The earliest tattoos consisted of lines and dots forming patterns. Images have been found on other mummies dating back almost 2500 years. The earliest known image found on a mummy is a tattoo of the Egyptian god Bes. ${ }^{4,5}$ Body decoration has evolved throughout the world at many sites independently of one another and has been used for beautification, religious expression, healing, and as a form of punishment. Mummies discovered in Russia and South America have demonstrated evidence of tattooing, and, together with mummies from Egypt that demonstrate tattoos, have shown that independent populations conceived the art of tattooing independently. ${ }^{4-7}$ Instructions on how to administer a tattoo were published as long ago as the 6th century, in the book Medicae Artis Principes, written by the Roman physician Aetius in the 1500s. ${ }^{8}$ Although there is no direct evidence for this, it is quite likely that the fickle nature of human beings that is present today was a characteristic of humans living long ago. Thus, there may have been attempts at tattoo removal dating back many millennia. However, modern tattoo removal began as a science approximately 20 years ago, with relatively few advances being made in recent times.

Many millions of people throughout the world are sporting a tattoo. The reasons for placing a tattoo are almost as varied as the designs themselves. One of the most common tattoos presenting for removal is the name of a significant other. Relationships may come and go, however the name of a once-loved one will remain if it is tattooed in the skin. The desire for removing such tattoos often occurs quite acutely. Today, tattoos are placed for decorative purposes, to signify a significant person, place, or thing, to identify with a group or gang, to express ones belonging to a branch of the military, as a rite of healing, or even for medical reasons such as marking an area of the body prior to administration of therapeutic radiation. Cosmetic tattoos are administered to replace lost eyebrows or to substitute for eyeliner, to cover scars, birthmarks, or even unwanted tattoos. Tattooing of the skin can also occur as a result of an injury or trauma. If a patient develops an injury to the skin and gets dirt, carbon from a pencil, ink, or other pigmented material in the injury, a traumatic tattoo can result. Soldiers often receive tattoos as a result of explosions and may have explosive particles embedded in their skin, which are hazardous to remove via laser. Whatever the myriad of reasons people get tattoos, the reasons for wanting them out may be just as varied.

\section{OBSOLETE METHODS OF TATTOO REMOVAL}

Attempts to remove tattoos must date back to the origins of tattooing. Historically, people have used abrasives to traumatize the surface of the skin, subsequently applying irritants and other compounds to the surface of the skin in an attempt to draw the tattoo particles out through the open wound. These practices have been in use for many decades, and perhaps beyond. Physicians have used dermabrasion with metal or diamond-coated fraises or abrasive salts (salabrasion), often with the addition of wound dressings that were thought to help remove tattoo pigment through the skin. Dermabrasion typically used a diamond fraise wheel or a wire brush to destroy the surface of the skin, which had been frozen with a topical cryogen to create a rigid surface to abrade. This technique has also been used in treating rhytides and acne scarring. When used on nonfacial skin, the risk of scarring from dermabrasion is significant. In addition, this procedure aerosolizes blood and tissue particles, which can be a hazard to the treating physician and other people participating in the procedure. Dermabrasion for the removal of tattoos is usually administered in a single treatment, although sometimes a series of treatments are used in an attempt to decrease the scarring that may occur from a single more intensive treatment. Utilizing multiple, less deep dermabrasion treatments can have the result of reducing scarring; however, there is virtually always some scarring, loss of normal skin pigment, and residual tattoo when using this method of tattoo removal. ${ }^{9-14}$

Using salt or other rough surfaces such as sandpaper can also remove the surface of the skin in the attempt to remove the tattoo. The resulting inflammation that occurs enables removal of some tattoo pigment. Salt is one of the more common agents used to abrade the surface of the skin. After salabrasion, a dressing may be applied that also contains salt. This dressing stimulates additional inflammation and cell injury that can result in even more tattoo pigment being removed. As is the case with dermabrasion, salabrasion or the use of sandpaper as an abrasive often results in significant scarring of the treated area, loss of pigment, and residual tattoo. These destructive modalities are not recommended for modern tattoo removal and carry a significant risk of hypertrophic scarring or keloid formation after the procedure. 


\section{THERMAL, CHEMICAL, AND SURGICAL MEANS OF TATTOO REMOVAL}

Extreme heat or cold can be used to destroy the superficial layers of skin, with resulting inflammation and tattoo removal, but with significant scarring. Almost any source of heat can and has been used in an attempt to remove tattoos at some point in time. Patients themselves have used cigarettes and cigars, heated metal objects, fire, and more controlled sources of heat in an attempt to destroy the superficial layer of the skin and thus the tattoo. Physicians use thermal methods of tattoo removal including destructive lasers, such as the carbon dioxide $\left(\mathrm{CO}_{2}\right)$ laser, which destroys the superficial layers of skin, effecting removing of a tattoo. These thermal methods of tattoo removal, however, almost always leave a scar. There appears to be a very narrow range of thermal heating that can effectively remove a tattoo in a single treatment without dramatically altering the skin surface. This is evidenced by the photograph shown in Fig. 1 of a patient who applied a cigar to her tattoo, effecting complete removal of this portion of the tattoo in a single treatment. It is very unlikely that she would be able to repeat this procedure again without leaving a significant scar and a good amount of residual tattoo behind. A device that thermally coagulates the surface of the skin in a way similar to that of a cigar is an infrared coagulator. This device was developed to apply heat to

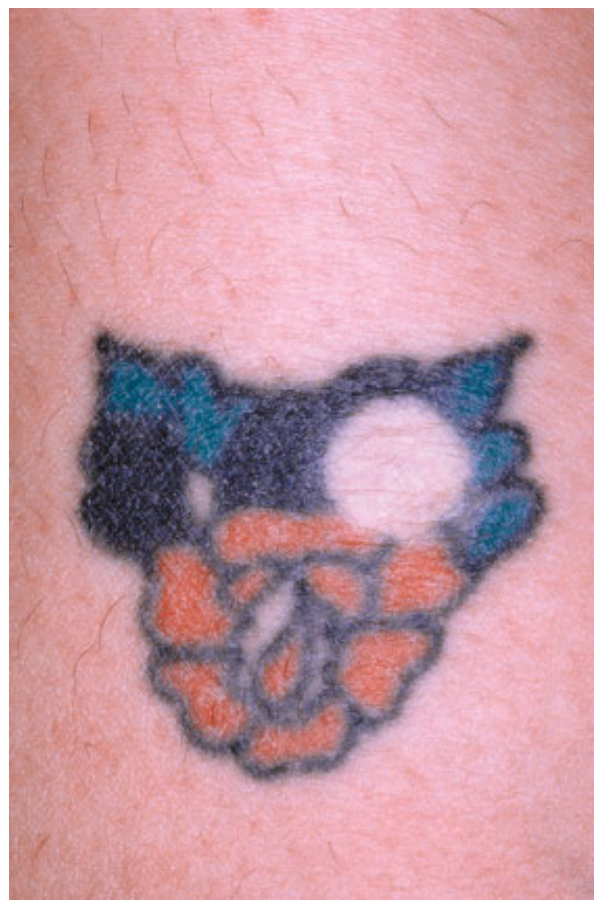

Figure 1 A patient attempted to remove her tattoo one evening in a bar with a lighted cigar. She was able to achieve complete removal in a given area in a single treatment, with little textural change. Unfortunately, the odds of performing this feat again are small, and the associated pain must have been a deterrent. the surface of the skin to remove a variety of lesions including tattoos. ${ }^{15-19}$ Electrocautery has been used as a destructive heating method to remove tattoos. In addition, the carbon dioxide laser targets water and heats the skin in a nonspecific manor, producing scarring while removing some tattoo pigment. On the opposite end of the thermal spectrum, liquid nitrogen has been used to destroy numerous superficial skin lesions, including tattoos. Virtually all of the above thermal methods for removing tattoos lead to incomplete tattoo removal with significant scarring. ${ }^{20-23}$

It is likely that tattoos have been removed for some time using surgical excision. This method effectively removes the entire tattoo but replaces it with a linear surgical scar. ${ }^{24-28}$ Larger tattoos require multiple surgeries and are often performed in a staged manner. Although surgical removal of tattoos is complete, it runs a significant risk of producing scars that can be debilitating because of the often varied locations of tattoos. Tattoos that are placed on acral locations may have insufficient loose skin for easy removal. In addition, tattoos in these locations may result in scars that restrict movement due to contraction. Staged removal of tattoos will limit the length of a surgical scar, and it is often the preferred surgical treatment. ${ }^{29-31}$ Surgical removal is preferable in situations where people are having allergic reactions to their tattoos. Attempts at laser removal in this situation may lead to anaphylactic reactions and is not advised. This includes treatment with the carbon dioxide laser.

Lasers have also been used to nonselectively remove tattoos by heating and tissue destruction since the 1970 s. $^{32-36}$ The argon laser is a laser that destroys tissue by nonselective heating and emits a blue or green continuous laser beam at 488 or $514 \mathrm{~nm}$. Although tattoos selectively take up this green light if they are black, because the lasers are not pulsed, nonspecific heating and tissue destruction takes place. Thus, the heat spreads from the tattoo granules to the surrounding skin, destroying not only the tattoo but also the skin. This results in scarring in a fashion similar to the carbon dioxide laser. The carbon dioxide laser emits at a wavelength of $10,600 \mathrm{~nm}$, targeting water as the chromophore. The carbon dioxide laser thus ablates superficial layers of skin, resulting in removal of some of the tattoo pigment with significant inflammation and results in scarring. This laser has been used for almost 25 years for tattoo removal, rarely removing the tattoo completely and almost always leaving a scar. ${ }^{37-39}$ The carbon dioxide laser is nonspecific but able to remove superficial layers of skin more selectively than some other nonspecific modalities. Nonetheless, the result is still most often partial tattoo removal with significant hypopigmentation and scarring (Fig. 2). The continuous argon laser produces a similar scarred appearance in treated tattoos as seen after carbon dioxide laser treatment. ${ }^{40-43}$ 


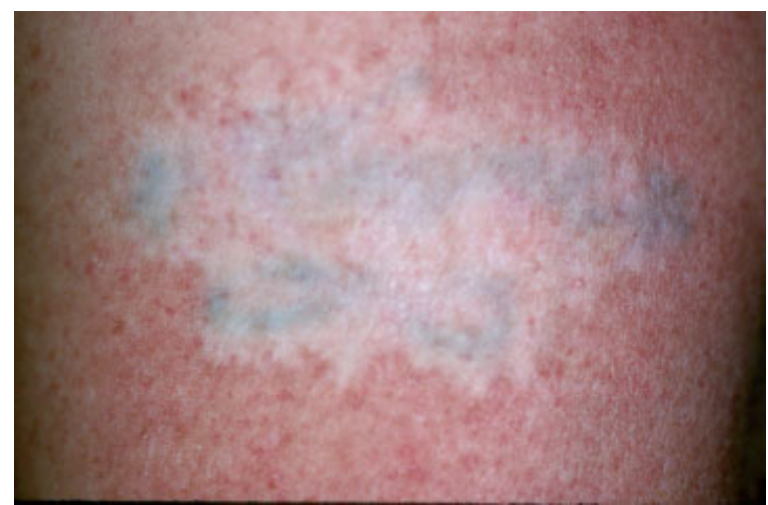

Figure 2 Tattoos removed with the carbon dioxide laser demonstrate significant scarring and residual tattoo pigment. This laser is not specific for tattoo particles and merely targets the water in skin.

These destructive modalities represent the first attempts to more selectively remove tattoos than previous chemical or abrasive techniques. They presaged the modern age of laser tattoo removal.

\section{MODERN Q-SWITCHED TATTOO REMOVAL LASERS}

Present-day tattoo needles inject ink granules into the superficial to mid-dermis. This ink placement necessitates deeply penetrating lasers to achieve tattoo removal. In addition, melanin pigment in the epidermis is extremely efficient at absorbing virtually all wavelengths of visible light into the infrared. Melanin pigment is predominately made to absorb ultraviolet radiation, and although its ability to absorb light decreases with increasing wavelength, melanin absorption is still a clinical problem for tattoo removal well into the infrared wavelengths. Tattoo-removing lasers must be absorbed by the tattoo granules to effect removal. Because today's tattoo pigments come in a myriad of colors, multiple wavelengths of light may be required to remove a single tattoo. In addition to variations in color, tattoos may become resistant to certain wavelengths of light in a manner similar to bacteria becoming resistant to antibiotics. Thus, multiple wavelengths of light may be required to remove even the simplest of colors to treat, such as black, with minimal or no scarring.

Shorter wavelengths of electromagnetic radiation scatter more than longer wavelengths. This even applies to electromagnetic radiation such as $\mathrm{x}$-rays. This is the reason why a greater dosage of radiation may be required to remove a skin cancer when treating with a smaller field of a radiation than when using a larger one. This is also the reason that the sky is blue. When viewed from outer space, the sky does not appear blue but is clear. The blue color is due to the scattering of the shorter visible wavelengths of light in the blue region by the atmos- phere toward our eye. This is also the reason that a setting sun appears deep red. Therefore, when treating black tattoos, the longest wavelength possible should be used when treating patients with dark skin types, such as Fitzpatrick skin types $\mathrm{V}$ and VI. When using longer wavelengths, the melanin pigment in the surface of the skin will absorb less of the laser energy minimizing epidermal damage, whereas the black tattoo should absorb all of these wavelengths almost equally. Because light scatters at the edge of the field, one should use the largest spot size possible when treating tattoos. When using a large spot size, the smallest percentage of the incident laser beam will be scattered, thus minimizing the percentage of the laser beam that is deposited superficially in the skin. ${ }^{44}$ Superficial deposition of laser energy will injure the epidermis and superficial dermis while not depositing most of the laser energy where it is really needed, at the site of the tattoo. One of the more common mistakes made by laser surgeons new to the field of tattoo removal is to keep increasing the laser fluence by shrinking the spot size in tattoos that have become refractory to a given laser. This deposits more of the laser energy superficially, and as a higher fluence is being used, results in an even greater incidence of damage to the epidermis and superficial dermis, and thus more scarring. Therefore, when a given laser seems to be losing its effectiveness in fading a tattoo, it is preferable to switch to an alternate Q-switched laser rather than simply shrinking the spot size and turning up the fluence with too small a spot size. Because black tattoo pigment, or for that matter black pigment of any kind, absorbs virtually every wavelength of light, all of the Q-switched lasers are effective at removing black tattoos. The fact that black absorbs almost every color of light is evidenced by walking outside on a hot summer day in bare feet. One quickly jumps to the grass or any white surface due to the extreme heat from visible and infrared wavelengths being absorbed in the black pavement. Although the most common tattoo pigment used today is still black, unlike 20 years ago when most tattoos were blue, black, or green, today's tattoos use a myriad of colors that literally span the rainbow (Fig. 3). Because modern tattoos use several colors, tattoo removal has become much more complicated. The one color of light we can almost guarantee will not work for treating a tattoo is light the color of the ink itself. When we see a green tattoo or a red tattoo, it is because the other colors are absorbed by the tattoo pigment and the green or red that we see is reflected away at our eye. Thus, if treating a tattoo with the color we see, it is quite likely that this color will be reflected away from the tattoo, thus failing to be absorbed and produce the effect of fracturing and heating the tattoo granules. Because the skin contains three major chromophores-hemoglobin, melanin, and water-lasers that are absorbed strongly by these wavelengths would have to compete with these chromophores 
A
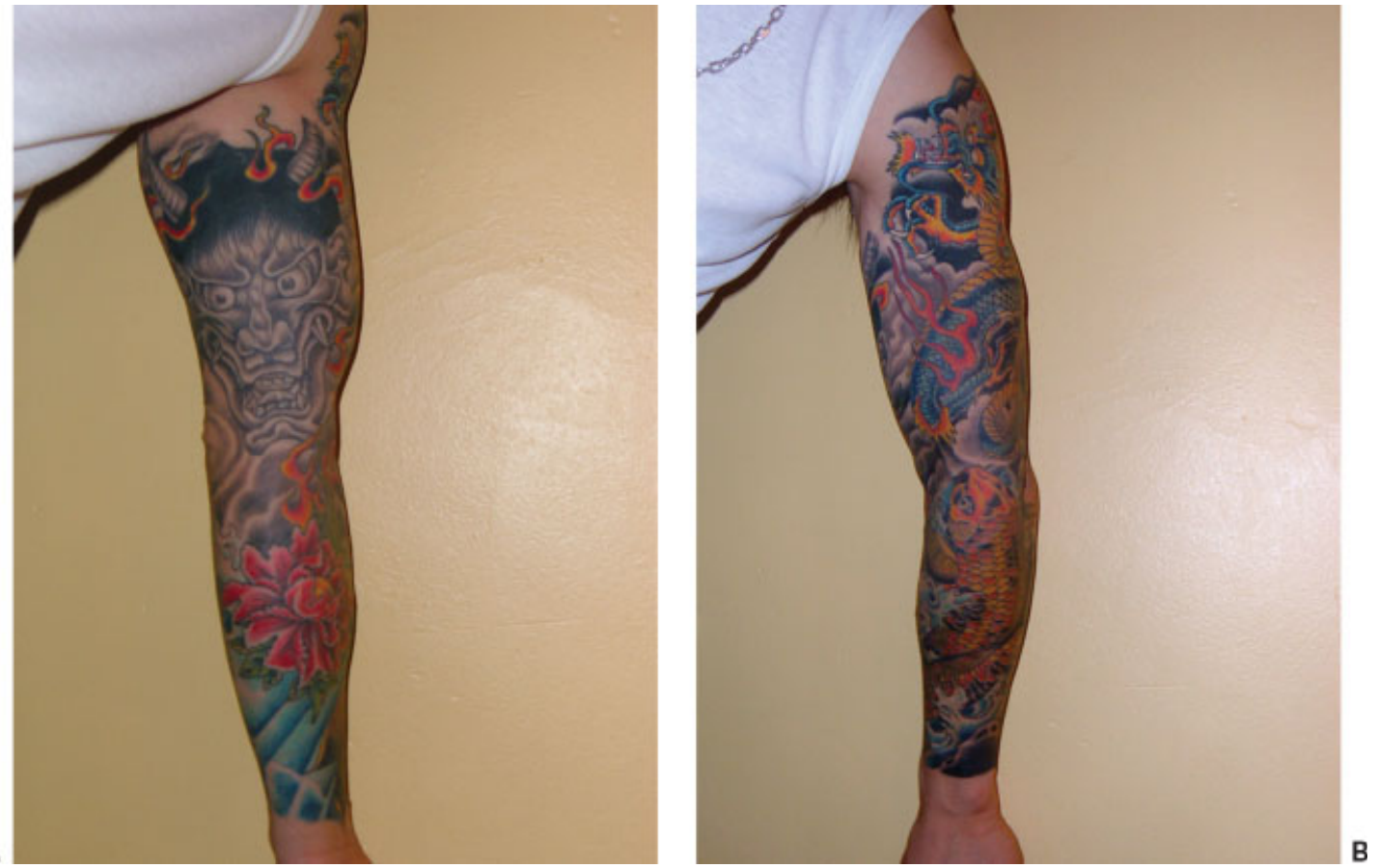

Figure 3 A modern, multicolored tattoo.

for absorption. Thus, the competing chromophores of melanin, hemoglobin, or water would take up some of the laser energy not allowing it to reach the tattoo granules. Currently available Q-switched lasers are ideal for tattoo removal in the sense that they are absorbed poorly by competing chromophores and penetrate deeply. They emit in the red and infrared wavelengths $(694 \mathrm{~nm}, 755 \mathrm{~nm}$, and $1064 \mathrm{~nm})$; the exception to this is the Q-switched neodymium:yttrium-aluminum-garnet (Nd:YAG) laser, which in addition to delivering $1064 \mathrm{~nm}$ also delivers $532 \mathrm{~nm}$. Although this wavelength is significantly absorbed by hemoglobin, it still is quite effective at removing red tattoo pigment. There are other lasers that use crystals to alter the emitted wavelength of Q-switched lasers, producing other wavelengths that are effective for removing some difficult-to-remove colors. The lasers available today for tattoo removal were not simply selected because they are the best wavelengths for removing tattoos. We are stuck with what current technology and physics allows us to have with regard to the Q-switched lasers. Ruby lasers were among the first lasers built, thus making this technology available for incorporation into tattoo-removing lasers. The wide range of colors that are present in today's tattoos often require the use of all three available types of Q-switched lasers to effect their removal, and removal may still be incomplete despite using all available Q-switched lasers.

Modern tattoo removal requires the use of Q-switched lasers of which there are three types: the $\mathrm{Nd}: Y A G$, ruby, and alexandrite lasers. Q-switching is a way of producing a very short laser pulse in the nanosecond range. Q-switched lasers were used to remove tattoo pigments as early as $1965 .{ }^{45,46}$ Goldman showed that the Q-switched ruby laser interacted with, and removed, dark tattoo pigments without leaving a scar. In addition, his research showed that laser pulses in the millisecond domain if used to treat tattoos would result in thermal damage to the treated area and a scar. ${ }^{45,46}$ More than 15 years later, Anderson and Parish in their groundbreaking manuscript in the journal Science described the concept of selective photothermolysis. Photothermolysis describes the ability to remove targets from within skin or other tissues without affecting the surrounding, uninvolved skin. These targets can be virtually anything that takes up laser energy such as blood vessels, melanin pigment, or tattoo particles. Anderson and Parish state that small particles such as tattoo granules should be treated with pulses in the nanosecond domain. ${ }^{47}$ Despite the plethora of work that has been done from the 1960s until now documenting that $\mathrm{Q}$-switched lasers are ideal for tattoo removal; physicians are still treating tattoos with devices that emit pulses of light energy in the millisecond range. Tattoos treated with lasers or intense pulsed light (IPL) devices that emit millisecond-domain pulses almost always result in incomplete removal of tattoos with significant scarring (Fig. 4). Q-switched lasers are the optimal devices for removing tattoos today. The three types of Q-switched lasers (Nd:YAG, alexandrite, and ruby) are the only devices that should be used to selectively remove tattoos. The exceptions to this case are tattoos that are small enough to be easily excised and those in which a person is having an allergic reaction, the latter of which are dangerous to remove with any type of laser. 


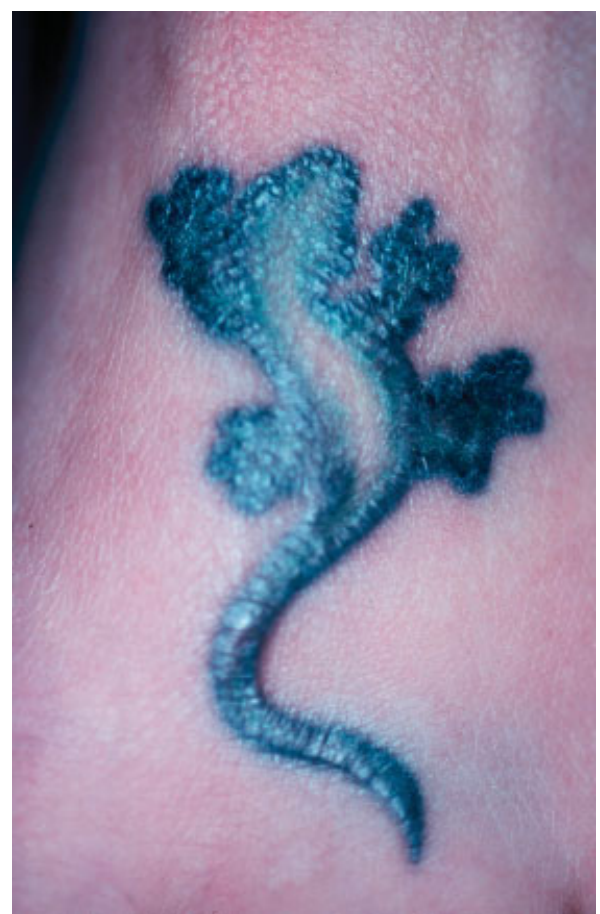

Figure 4 A tattoo treated with an intense pulsed light device that emits a millisecond-domain pulse, with resultant keloidal scarring and significant residual tattoo.

\section{Q-SWITCHED RUBY LASER}

One of the first lasers ever developed for application to skin surgery was the ruby laser. The Q-switched ruby laser was also the first laser developed for treating pigmented lesions and tattoos. ${ }^{45,46}$ This laser is extremely effective at removing black and blue tattoo pigments and unwanted melanin pigment. In fact, this laser even temporarily removes normal melanin pigment from skin, but because of the deep location of melanocytes surrounding hair follicles, areas depigmented by the Q-switched ruby laser will repigment in the months after treatment. Because amateur tattoos typically utilize India ink and are generally placed while using a straight needle and not an electric professional tattoo needle, these tattoos respond much more quickly to laser removal than do professionally placed tattoos. There are, however, several amateur tattoos that have proved to be quite resistant to removal with any of the $\mathrm{Q}$-switched lasers (author's personal experience). The difficulty in removing some amateur tattoos results from the fact that individuals can now acquire professional tattoo needles over the Internet and because several dyes are being used that are either professional tattoo inks ordered over the Internet, or at the opposite end of the spectrum, virtually any substance such as burnt plastic from toothpaste tubes that are being scraped to create black inks. Homemade "inks" can be extremely difficult to remove. More than 15 years ago, Taylor et al demonstrated removal of amateur and professional tattoos using the Q-switched ruby laser. They used a ruby laser with a 40- to 80nanosecond pulse-duration using fluences that ranged from 1.5 to $8.0 \mathrm{~J} / \mathrm{cm}^{2}$. The highest fluences used resulted in the most tattoo clearance, with 4 to $8 \mathrm{~J} / \mathrm{cm}^{2}$ representing the optimal fluences. These authors demonstrated substantial lighting or complete removal in 78\% of amateur tattoos but in only 23\% of professional tattoos. Of the 57 tattoos treated in this study, only one developed scarring. ${ }^{48}$ Although Q-switched lasers were invented so many years ago, very few improvements have been made to them over the 15 years since their development. Q-switched lasers remain the optimal method for tattoo removal. Scheibner et al published a study of the Q-switched, 694-nm ruby laser to treat 163 tattoos, 101 of which were amateur tattoos and 62 of which were professional tattoos. They used a 5- to $8-\mathrm{mm}$ spot size and energies ranging from 2 to $4 \mathrm{~J} / \mathrm{cm}^{2}$. An average of three treatments was administered to each tattoo. In this study as well, amateur tattoos responded the best with complete removal in 4 tattoos and almost complete removal in 84 , with significant pigment removal in 11 and minimal removal in only 2 . Of the professional tattoos that were treated, 2 achieved complete removal, nearly complete removal was achieved in 5, and 18 had significant removal, and only minimal removal was seen in 25 with little removal in 12 . Professional tattoos that had yellow, red, or green pigment faded less than the black tattoos, as would be expected. These authors reported no scarring in any of the treated patients. ${ }^{49}$

Ruby lasers are quite effective at removing black and dark-blue tattoo pigments (Fig. 5). Of course, amateur, traumatic, and medically placed tattoos (which are equivalent to amateur tattoos) respond quite well to the Q-switched ruby laser. ${ }^{50}$ However, Anderson and Kilmer have shown that the ruby laser also effectively removes not only black pigment but blue and green pigments as well. ${ }^{51}$ In addition, ruby lasers are also effective at removing some colors that one would not expect to respond to the ruby laser such as red (personal observations). The ability to remove red or orange pigments is surprising, as one would expect the red ruby laser light to be reflected away from the red tattoo pigments. Still, these colors are removed to a much lesser extent than the darker colors. Future studies should focus on optimizing the Q-switched ruby laser to better remove the myriad of pigments that we are seeing in today's tattoos and possibly explore the mechanism that these lasers use to remove red tattoo pigment.

\section{Q-SWITCHED Nd:YAG LASER}

The Nd:YAG laser emits in the infrared region at $1064 \mathrm{~nm}$. That wavelength of light is invisible to the human eye but reacts with tissue in a similar fashion to the ruby and alexandrite wavelengths, which would appear red when viewed. Q-switched Nd:YAG lasers 
A
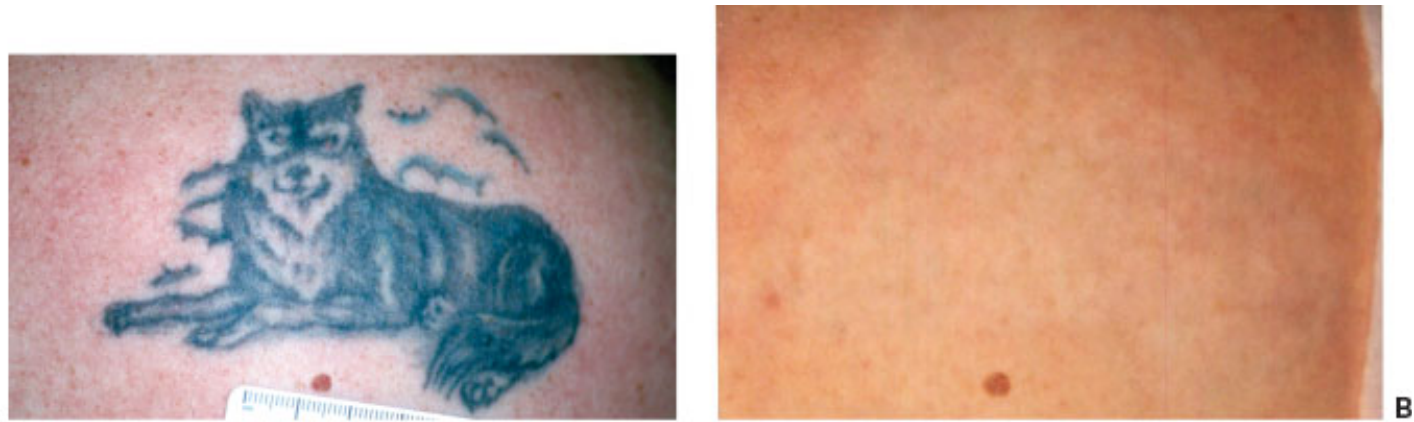

\section{B}
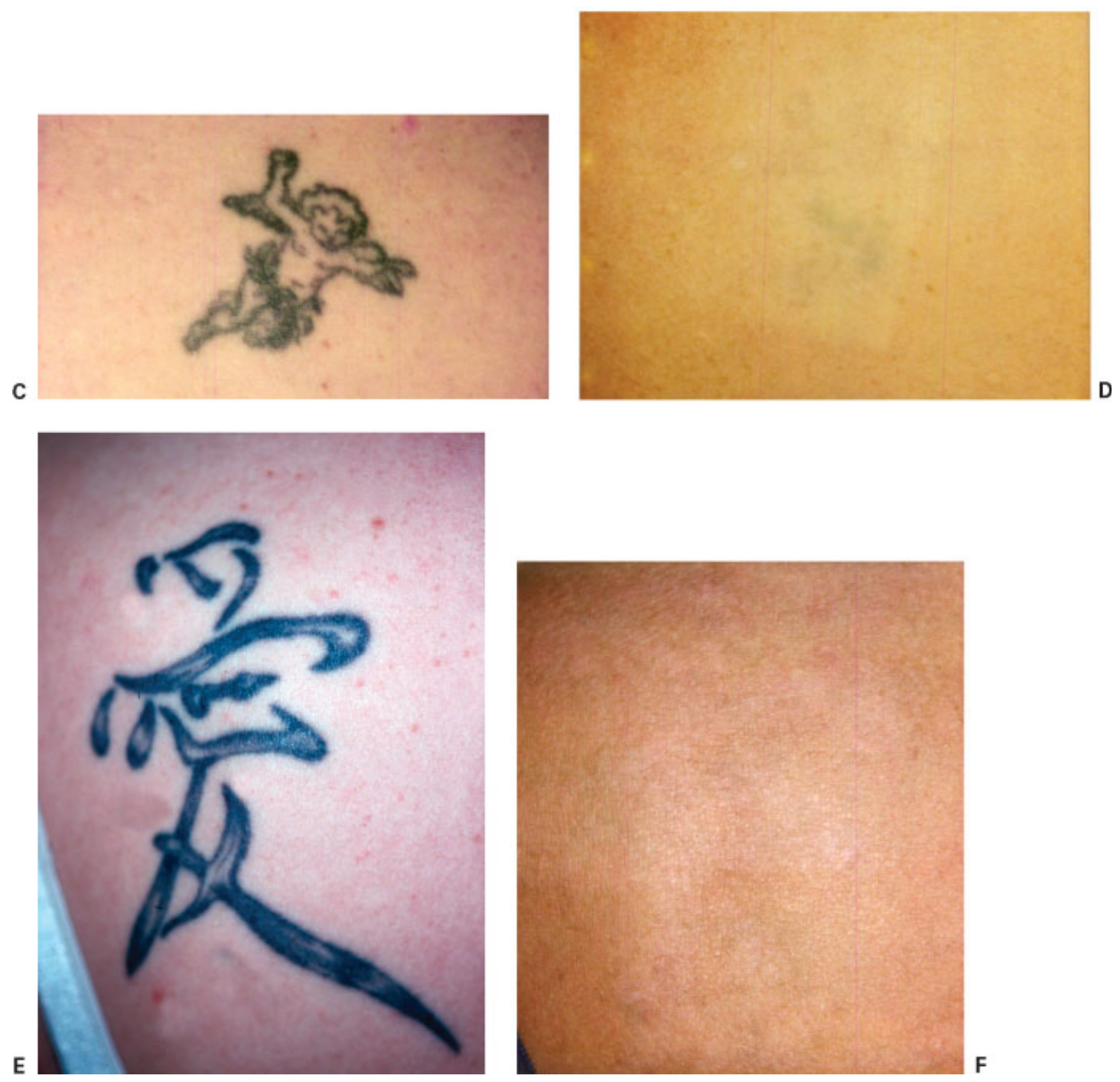

Figure 5 Black tattoos before $(A, C, E)$, and after $(B, D, F)$ a series of treatments with the Q-switched ruby laser.

also contain a potassium titanyl phosphate (KTP) crystal in addition to the Nd:YAG crystal, which doubles the frequency of the 1064-nm laser light, thus producing $532-\mathrm{nm}$ green light from the same machine. Thus, Q-switched Nd:YAG lasers are capable of emitting two wavelengths of light, both 1064-nm and 532-nm laser energy. This versatility enables treatment of dark tattoo pigments, such as black and dark-blue, using the 1064-nm wavelength, as well as the treatment of red, orange, and some yellows using the 532-nm wavelength. When treating a tattoo, it is quite obvious that the infrared 1064-nm wavelength is not absorbed into the red tattoo pigments. When blanketing a tattoo, one can easily see the black or blue pigment turning white immediately after treatment with the laser, whereas the red pigment appears as if it has been avoided throughout the laser treatment. The converse it true when using the $532-\mathrm{nm}$ wavelength. The greatest effect is seen when 
A

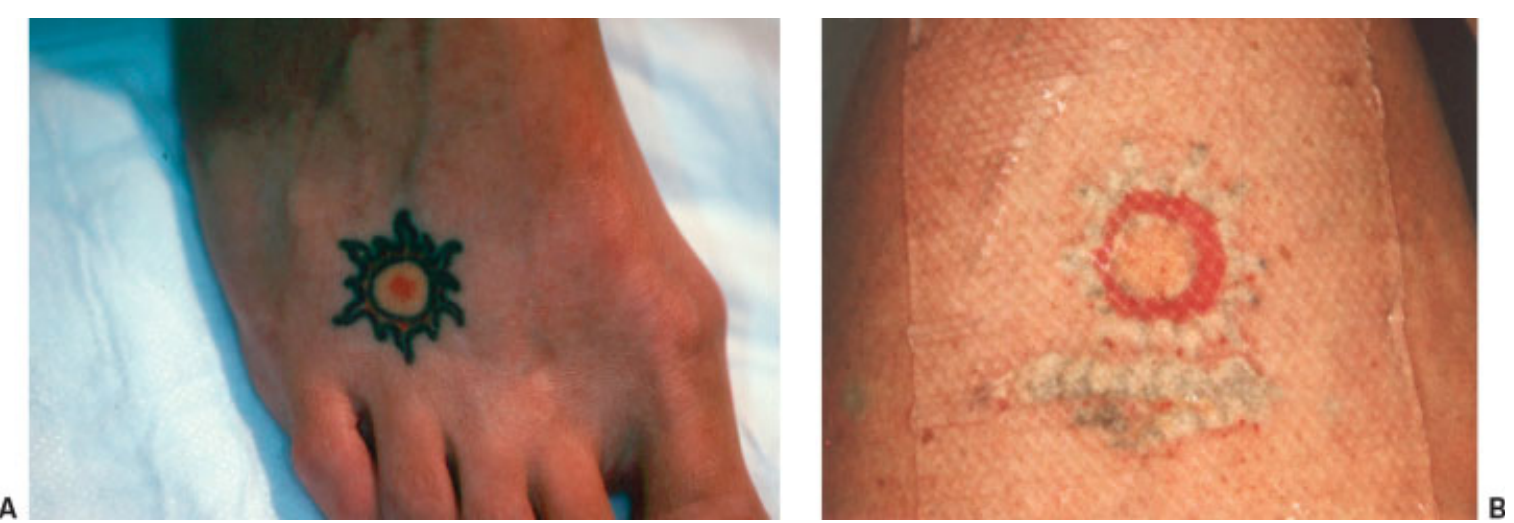

Figure 6 A multicolored tattoo containing red immediately after treatment with a Q-switched ruby laser is shown. Although the entire tattooed area was treated, the red pigment appears as if it was intentionally avoided.

treating the red tattoo pigments, although some minor effect may also be seen on black. Sparing of the red tattoo pigment when using an infrared wavelength is easily seen after treatment (Fig. 6). Kilmer's group published findings of treating 39 tattoos using the Q-switched Nd:YAG laser with fluences ranging from 6 to $12 \mathrm{~J} / \mathrm{cm}^{2}$. In their study, greater than $75 \%$ removal of black pigment was accomplished in $77 \%$ of patients, and $90 \%$ clearance was noted in $28 \%$, after only four treatments. Colors other than black were removed less effectively in the study. The $1064 \mathrm{~nm}$ is less well absorbed by epidermal melanin pigment than other Q-switched wavelengths, and as expected, pigmentary alterations or scarring was not noted in their study. ${ }^{52}$ Because of the decreased melanin absorption at the long 1064-nm wavelength as compared with the 694-nm ruby or 755-nm alexandrite laser, treatment of darkly pigmented individuals is accomplished using the Nd:YAG laser with less risk of injuring epidermal melanin pigment and thus less risk of subsequent scarring. Jones's group reported on 15 tattoos treated with the Q-switched Nd:YAG laser in darker-skinned patients having Fitzpatrick type VI skin. More than half the tattoos treated in their study were rated as being 75 to 95\% improved after three to four treatments. Slight skin lightening was noted in only two patients in this study, and no scarring or textural changes were reported. ${ }^{53}$ The $\mathrm{Nd}$ :YAG laser offers a very rapid repetition rate of up to $10 \mathrm{~Hz}$ (pulses per second) and relatively high peak powers. One currently available Nd:YAG laser offers a maximum energy density of $3.5 \mathrm{~J} / \mathrm{cm}^{2}$ when delivering a true 6-mm spot size, all this with a repetition rate of up to $10 \mathrm{~Hz}$ (C6, Q-switched Nd:YAG laser; Hoya Con Bio, Freemont, CA). In addition, the C6 Nd:YAG laser offers hand pieces that contain a dye-impregnated polymer that converts $532-\mathrm{nm}$ laser light to $585-\mathrm{nm}$ or $650-\mathrm{nm}$ light, thus doubling the number of wavelengths that are available from this single laser and enabling the removal of more varied tattoo colors that we often see in today's multicolored tattoos.

\section{Q-SWITCHED ALEXANDRITE LASER}

The Q-switched alexandrite laser emits at a wavelength of $755 \mathrm{~nm}$, intermediate between the ruby laser at $694 \mathrm{~nm}$ and the Nd:YAG laser at $1064 \mathrm{~nm}$. Alexandrite lasers are capable at removing blue and black pigments, as well as having been credited with the ability to remove green tattoo pigments better than any other laser. Green is often the only color left behind after treatment with Nd:YAG lasers and may be the most stubborn color for any other laser type to remove as well (Fig. 7). The alexandrite laser has become know as the treatment of choice for removing green tattoo pigment, although like the other types of Q-switched lasers, it is also quite effective at removing black and blue tattoo pigments. Fitzpatrick and Goldman published a series of $25 \mathrm{pa}^{-}$ tients having both professional and amateur tattoos and reported 95\% removal of tattoo pigment in an average of 8.9 treatment sessions. Temporary hypopigmentation was noted in $50 \%$ of patients, and $12 \%$ noted transient textural changes to the surface of the skin. These authors concluded that the Q-switched alexandrite laser was safe and effective for removing blue and black tattoo pigments. ${ }^{54}$ Alster published on the ability of the Q-switched alexandrite laser to effectively remove tattoos, examining 24 professional and 18 amateur tattoos. Professional tattoos required an average of 8.5 treatments for total removal, whereas the amateur tattoos only require 4.6 treatments on average. ${ }^{55}$ The alexandrite laser offers a wavelength and a repetition rate that is in-between the Nd:YAG and the ruby lasers and also offers relatively high energies. One currently available alexandrite laser delivers up to $5.5 \mathrm{~J} / \mathrm{cm}^{2}$ using a $4-\mathrm{mm}$ spot and a repetition rate of $5 \mathrm{~Hz}$ (ALEXlazr, Candela Corporation, Wayland, MA). 
A
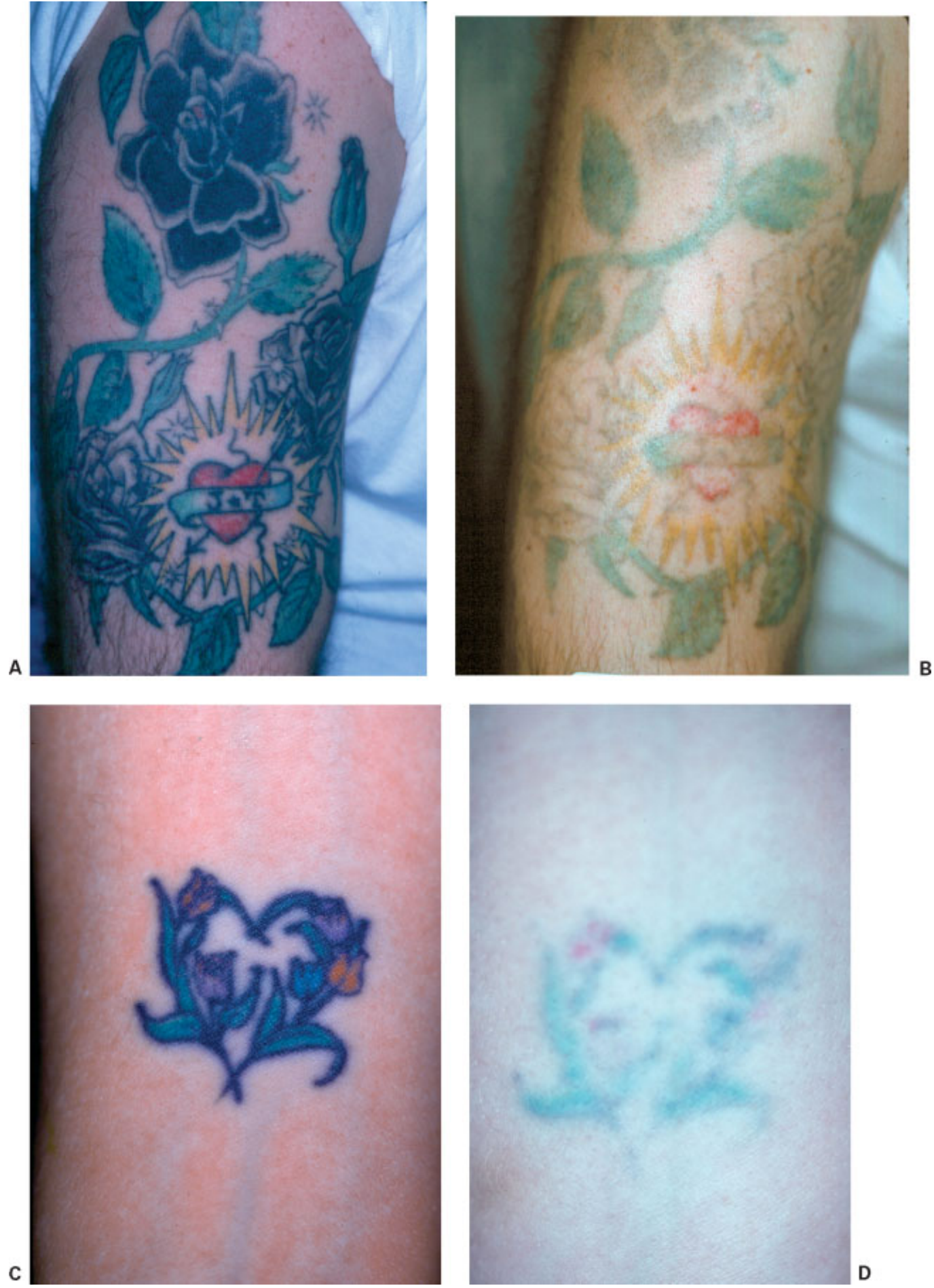

Figure 7 Tattoos containing green before (A, C), and after (B) multiple treatments with Q-switched Nd:YAG and alexandrite lasers, or the Nd:YAG and ruby lasers (D). Residual green pigment can be seen in both cases.

\section{SUMMARY}

The three types of Q-switched lasers were compared for effectiveness by Leuenberger et al. These authors looked at the ability of these lasers to remove blue-black tattoo pigments and found that the ruby had the greatest clearance rate of the three but also the highest incidence of hypopigmentation. ${ }^{56}$ Comparative studies such as this are very hard to perform, as one must look at the highest tolerated fluences available from each device. Because these devices vary in the spot sizes they offer as well as varying slightly in the pulse durations, although all are in the nanosecond domain, comparisons are difficult. In addition, improvements are constantly being made to all these lasers, thus making it difficult to compare currently 
available models. Zelickson's group studied the clinical, histopathologic, and ultrastructural effects of all three types of laser using an animal model. These authors found that the red-brown, dark-brown, and orange pigment responded best the to Nd:YAG laser, whereas the alexandrite laser was most effective for removing blue and green pigment, and the Q-switched ruby laser was most effective for removing purple and violet pigment. The 532-nm wavelength of the Nd:YAG laser was considered best for removing red pigment. All these lasers were found to be relatively equivalent for removing black tattoo pigments. ${ }^{57}$ In modern clinical practice, having only one laser for removing tattoos may suffice for removing black tattoos only. However, even when treating black tattoos, they may become refractory to a single type of laser, necessitating the use of another type of tattoo laser to achieve complete removal. More frequently, physicians simply increase the laser energy to tattoos that are becoming refractory to a given wavelength, and this is accomplished by shrinking the spot size. Shrinking the spot size and increasing the energy deposits most of the laser energy in the epidermis and the superficial dermis, an area that does not even contain the tattoo. This practice significantly increases the likelihood of producing a scar. Physicians must fight the urge to keep "turning up their laser" and instead bundle their cases of refractory tattoos and bring in a second laser on a specific day. Physicians may rent the type of laser that they do not currently have in their office and will get better clearance when bundling their resistant tattoos on a specific day for one of the alternate types of Q-switched lasers. Once tattoo removal becomes a large part of a practice, it should be cost-effective for that practice to purchase a second a Q-switched laser. Each of these three Q-switched lasers has its benefits, and determining the appropriate laser for a given practice depends upon the number and color of tattoos that are seen, as well as the skin type of patients presenting for tattoo removal. If tattooing becomes even more widespread than it is today, the request for tattoo removal will increase exponentially. Future innovations in laser technology as well as newer, easierto-remove tattoo inks should enable more effective tattoo removal in the future, possibly requiring only a single device.

\section{FUTURE ADVANCES}

Lasers with even shorter pulse-durations than the Q-switched lasers are being tested in an effort to more effectively remove tattoos and optimize tattoo treatment. Lasers that emit in the picosecond range are now being developed and tested for this purpose. Ross' group compared two Nd:YAG lasers for effectiveness at removing black tattoo pigment, one a 10-nanosecond pulse-duration laser and the other a 35-picosecond pulse-duration laser. Sixteen tattoos were treated at 4-week intervals for four treatments. In 12 of the sixteen tattoos, the picosecond laser yielded greater removal of tattoo pigment. ${ }^{58}$ In addition to developing better lasers, other advancements have been made to improve the optical properties of the skin, thus allowing the laser light to more easily reach the tattoo in the mid-dermis. Topical and injected solutions that decrease scattering due to dermal collagen have been developed. These index-matching agents make it easier for us to see the tattoo in the middle of the skin and thus would make it easier for tattoos emitting in the visible or near-visible range to "see" the tattoo as well. These optical clearing agents should enable one to remove a tattoo more effectively while significantly decreasing side effects. ${ }^{59}$ In addition to improving lasers and improving the optical properties of skin, new tattoo inks are being developed that should be easier to remove from skin. These inks contain pigments encapsulated in tiny tattoo particle-sized beads made of polymethylmethacrylate (PMMA) (Infinite Ink; Freedom-2, L.L.C., Conshohocken, PA). Encapsulating pigments in beads enables the use of alternate safer pigments, which may be too small in size to function as a conventional tattoo, to be encapsulated in beads that are the optimal size for creating a tattoo. Some of these pigments are much safer than the currently available tattoo inks, which are not regulated by the U.S. Food and Drug Administration, and often contain heavy metals and other potentially toxic ingredients. In addition to containing the desired color for the tattoo, the beads may also contain a target pigment that causes the bead to rupture when treated with a single laser pulse. Once the bead ruptures, the pigment is cleared in a fashion similar to what occurs after removal of a conventional tattoo. The difference is that when lasering a tattoo made from encapsulated pigments in PMMA beads, the tattoo should theoretically be able to be removed in a single laser treatment. Thus, changing the laser inks that are the targets for laser treatment, the properties of the skin that contains them, as well as the lasers used to treat tattoo pigments should enable more effective, less costly, and more complete tattoo removal in the future (Fig. 8).

\section{LASER TREATMENT}

\section{Initial Patient Consultation}

The key to having a satisfied patient is setting realistic expectations from the beginning. Patients presenting for tattoo removal often believe that the laser erases a tattoo, like one would erase pencil from a piece of paper. This means, that they often expect the treatment to completely remove the tattoo in a single session. In addition, coming in they know that the cost of their tattoo is generally only a few hundred dollars (however, tattoos 

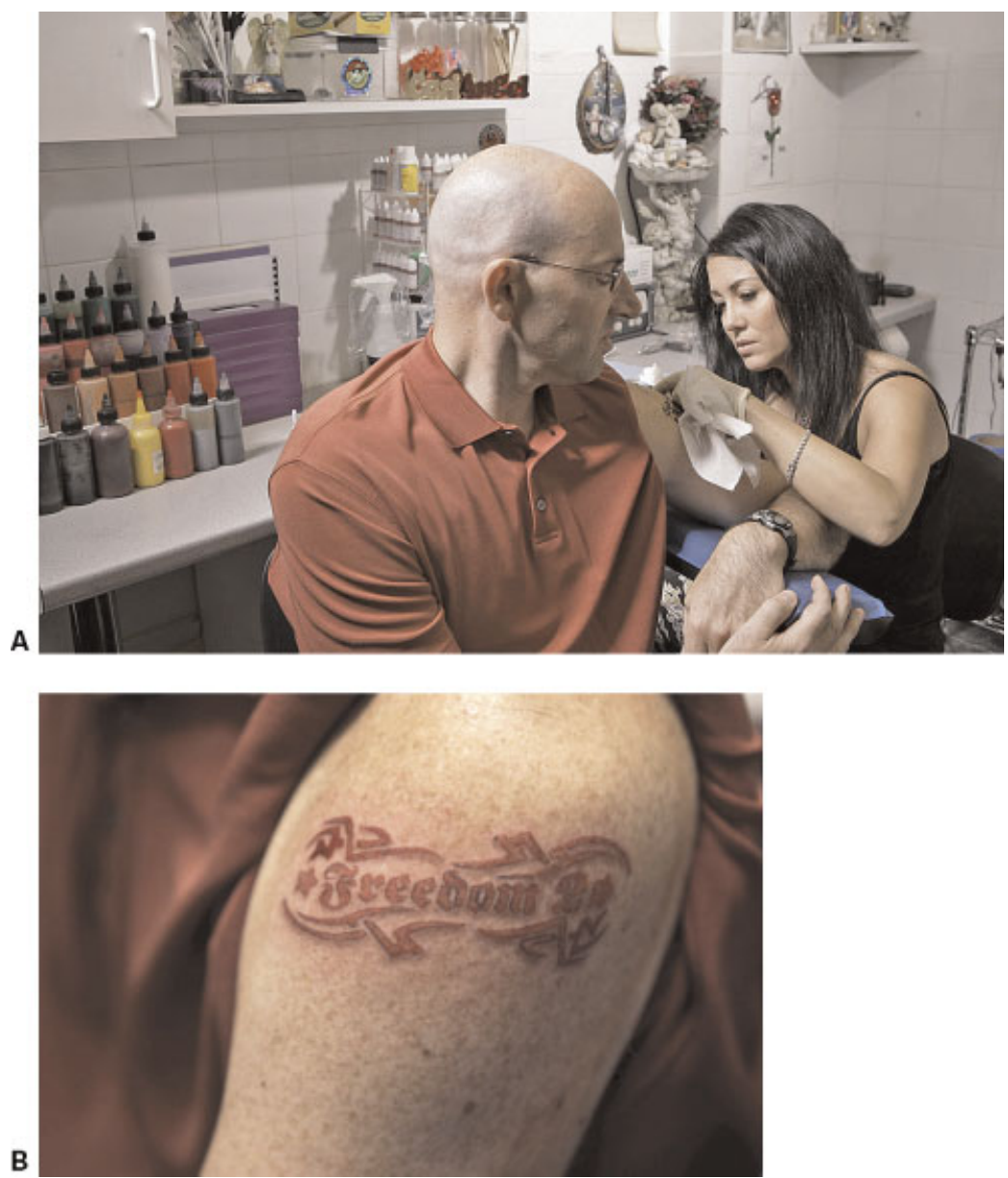

Figure 8 (A) The first Freedom-2 tattoo is being placed in the arm of the CEO of Freedom-2, Martin Schmieg. (B) Orange is normally one of the hardest colors to remove by laser. This tattoo has been removed with a single treatment.

today can cost into the thousands of dollars), but getting a tattoo removed will almost always cost in the thousands of dollars when adding up the total price over a series of treatments. The fact that patients expect tattoos to be removed in a single treatment is often reflected by the many people presenting prior to an important event such as a wedding or anniversary with the expectation that the tattoo can be removed a few weeks prior to that event.

The initial consultation is not only important for the patient who must leave with realistic expectations but is also important for the physician to identify those patients who will be noncompliant or have unrealistic expectations. Not every patient that walks through the door asking for treatment should be treated, and some patients who are unrealistic or express that they will be noncompliant should be turned away. To address unrealistic expectations, the physician may almost feel like he or she is trying to talk the potential patient out of having the procedure. If this is done appropriately, you should have a patient whose expectations are somewhat less than what you can actually deliver. When a physician begins to offer a new treatment, there is innate tendency to try to make a patient feel more positive about the procedure than they should. This positive feeling will only persist for the initial visit and can prove to be quite a trap for the relationship going forward. The first thing I point out in an initial consultation is that it may only take a day or two to get a tattoo, but it often takes 6 to 10 treatments or more to remove the tattoo. This of course depends upon the type of ink used, the skin pigmentation of the individual bearing the tattoo, and other factors. Thus, if a tattoo is going to take 6 to 10 treatments to remove, and treatments are spread out over 6 to 8 weeks, more than a year will pass before the tattoo will be removed. Pointing this out to the patient is critical. In addition, it is also critical to inform the patient that they will have to pay for the treatment each time they come to the office. Some patients have it in their mind that the payment for a single treatment session is for the removal of that tattoo, however long it takes. As a final note in my initial consultation, I tell the patient that the end result will depend $50 \%$ on how well I treat them with the laser and $50 \%$ on how well they follow the posttreatment instructions for care of the lasered site. I also warn each patient that some of the 
tattoo may be left behind, although it is quite possible that this will not be the case.

\section{SKIN CARE INSTRUCTIONS}

\section{Pretreatment}

The main chromophore that competes with the tattoo for absorption of the laser light is melanin pigment. Although the wavelengths used for tattoo removal are in the red and infrared region and thus poorly absorbed by melanin, there still is a significant amount of melanin absorption of these wavelengths. Fortunately, hemoglobin does not absorb well in these wavelengths and is thus not a major competing chromophore. The notable exception to this is when using the $532-\mathrm{nm}$ wavelength to treat red, orange, or yellow tattoo pigments. In normal situations, all of our melanin pigment resides in the epidermis, which overlies the tattoo granules residing in the mid-dermis. Thus, in order for the laser light to even reach the tattoo, it must traverse the epidermis and in doing so will be absorbed by epidermal melanin pigment. Absorption of laser light in epidermal melanin pigment does result in some damage occurring to the epidermis. Applying a hydrogel dressing prior to administration of the laser treatment provides some protection for the epidermis and is discussed below. In individuals with Fitzpatrick skin types III through VI, or in any individual who is tan, I use bleaching agents prior to laser treatment. I will often pretreat the tattoo site with an $\alpha$-hydroxy acid lotion or cream combined with a topical corticosteroid cream and/or a hydroquinone cream. Commercially available cream combining tretinoin, hydroquinone, and fluocinolone acetonide is available (Tri-Luma Cream; Galderma Laboratories, Fort Worth, TX). Tri-Luma Cream is quite effective for lightening the epidermis in patients with a tattoo, however because it contains tretinoin, it may be found irritating in some patients. Bleaching agents are often used before not only the initial treatment but also prior to subsequent treatments, as epidermal disruption due to laser treatment can result in deposition of epidermal melanin in the dermis. Agents that are used for bleaching will often lighten this dermal pigment, and I try to use them prior to subsequent laser treatments in individuals experiencing posttreatment hyperpigmentation. To identify with significant posttreatment hyperpigmentation, one can blanch the skin (diascopy) and get a good indication of which tattoos have significant postinflammatory hyperpigmentation. Using excessive laser fluences in patients who are darkly pigmented or who have significant postinflammatory hyperpigmentation in their tattoos probably increases the risk of scarring in these patients. Although it may not seem cost-effective in the short run, sending patients away who are either tan, deeply pigmented, or who have posttreatment hyperpigmentation is the wise thing to do.

\section{Treatment}

In general, tattoo removal probably hurts more than getting a tattoo. In addition, many tattoos are placed in a single treatment, whereas tattoo removal is the hurt that keeps on hurting. So with the exception of very small tattoos, where a needle stick would almost feel the same as a single pulse of the laser, I administer a local anesthetic prior to laser treatment. Some patients do prefer to use a topical anesthetic, and for this I use a $4 \%$ lidocaine cream (LMX 4; Ferndale Laboratories, Inc, Ferndale, MI). This cream is left in place over the tattoo for approximately 40 minutes prior to laser treatment. When patients need to have numbing cream applied, I perform this service at my office to give me control over the amount of cream the patients are applying and to ensure that it is applied properly. However, for the majority of patients who choose this route, the anesthesia is not sufficient and either during that treatment or for the subsequent treatment most choose to have local infiltration with buffered $1 \%$ lidocaine with epinephrine. Patients who are hurrying and wish to be lasered immediately after the injection of lidocaine will only make this mistake on one visit. It takes 5 to 10 minutes for the full anesthetic effect, and I always leave the room while my nurse applies the hydrogel dressing and return after the lidocaine has taken effect.

Prior to laser treatment, I cover all of the tattoos that I am about to treat with a clear hydrogel dressing. We use Vigilon (C.R. Bard, Inc, Covington, GA). Vigilon dressings are $\sim 96 \%$ water and help protect the epidermis by acting as a heat-sink. In addition, because Q-switched lasers emit pulses in the nanosecond domain, skin and blood can splatter and be aerosolized during tattoo removal. The splattering of tissue is either because of a rapid heating of the skin surface due to the very short pulses and high peak powers delivered by Q-switched lasers or because a shock wave is generated by these extremely short pulses, or perhaps by a combination of these effects. When using a clear hydrogel dressing, there is almost no splatter of skin or blood. If there is any bleeding, it usually occurs underneath the hydrogel dressing, which can be changed to a nonstick dressing after treatment. When treating without hydrogel dressings, there can be significant aerosolized blood and tissue, which is not only a hazard to the treating physician but also obscures the treatment site. When applying this dressing to a tattoo, it is extremely important to remove both of the clear plastic coatings on the outside of the dressings. These coatings help the dressing to stay moist during shipping. When these hydrogels are used as a wound dressing, only a single plastic surface is removed, and the other plastic surface facing away from the wound is left in place to slow down the drying out of the dressing. One should be extremely careful not to leave either of these plastic layers on when treating a tattoo. The physician should feel the dressing 
to ensure that both sides of the dressing are sticky, to ensure that one of the plastic coatings was not inadvertently left in place. If the plastic coating is left in place, it may heat up and melt during laser treatment or reflect the laser energy away from the tattoo. Vigilon has two clear plastic coatings to protect the soft, rubbery hydrogel material beneath. It is often difficult to see the plastic coatings on this dressing when they are in place. Both of these must be removed. We generally peel off one of the plastic coatings and apply the dressing to the tattoo site, and peel the other coating off immediately before treatment. If this is not done and both sides are peeled off, more often than not, the hydrogel dressing becomes stuck to the physician's white coat, the examination table, or a location to be discovered later.

\section{Posttreatment}

Posttreatment wound care is critical to obtaining a good cosmetic result when performing laser tattoo removal. I emphasize to the patients that the final result depends as much upon how well they take care of their treatment site as it does on my ability to properly laser their tattoo. After laser treatment, we apply paper tape over the hydrogel dressing and instruct the patient to change this hydrogel dressing to a nonstick dressing (Telfa; Kendall Medical Device Co., Mansfield, MA) over top of an occlusive ointment that does not contain antibiotics (Aquaphor; Beiersdorf AG, Hamburg, Germany), using paper tape to keep the dressing in place. If the hydrogel dressing becomes dried out before the patient is ready to remove it, we instruct them just to soak it off in the shower or bath, and never pull a dressing off that is stuck to a treatment site. Patients should be told to expect some crusting and scabbing that could last for 7 to 10 days after the treatment. In addition, patients may become blistered after their laser treatment, and these blisters may be extremely large (Fig. 9). We instruct our patients not to un-roof blisters

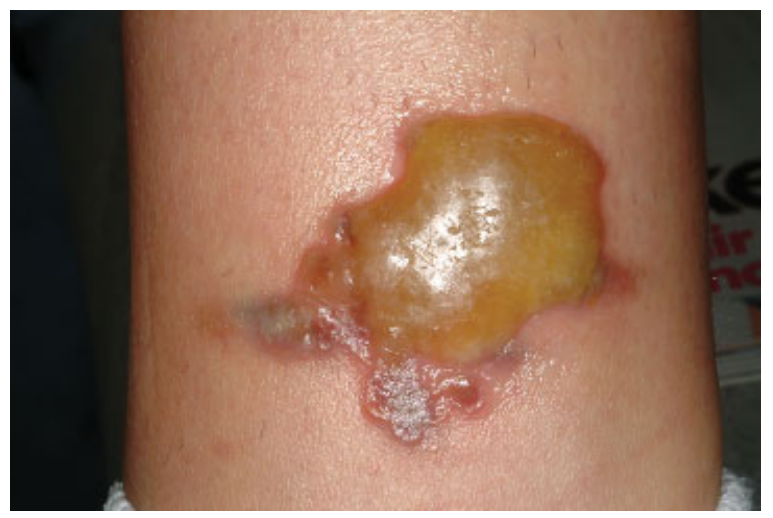

Figure 9 Blistering in the tattoo of a patient treated 3 days earlier with the Q-switched ruby laser. The treatment site healed without any scarring. if possible. If the blisters become too uncomfortable, I request that they come to the office so the blisters can be sterilely lanced and a dressing placed. I strongly urge the use of Aquaphor ointment as opposed to a topical antibiotic ointment. On the few occasions I get calls from patients telling me that they believe they have a wound infection, it is most often a contact dermatitis to one of the topical antibiotics I have told them not to use posttreatment. Because of the widespread use of topical antibiotics, allergies to them are becoming more and more common. Most dermatologists have moved away from using triple antibiotic ointments containing neomycin because in the past, allergic reactions to this antibiotic were so common that neomycin is included as an allergen on the standard patch test kits used to test patients for topical allergies. However, allergies to other topical antibiotics are becoming more common in patients seeing dermatologists, due to the avoidance of the triple antibiotic ointment and use of other topical antibiotic preparations. In the absence of Aquaphor ointment, I instruct patients simply to use petrolatum.

\section{PITFALLS TO AVOID IN LASER TATTOO REMOVAL}

\section{Wrong Device}

It has been more than two decades since Anderson and Parish published their landmark paper describing selective photothermolysis - the ability to selectively remove target tissues using pulses of laser energy. They stated that nanosecond-domain pulses were ideal for removing melanin-containing structures and other small particles, whereas microsecond-domain pulses were ideal for treating larger structures such as the vessels comprising port wine stain birthmarks. ${ }^{60}$ Despite this publication and many others demonstrating the effectiveness of nanosecond-domain pulses for tattoo removal, devices that emit pulses in the millisecond domain such as IPL sources are still used to treat tattoos even today. Devices with millisecond-domain pulses heat tattoo granules for too long, allowing heat to spread to the surrounding tissue thus damaging it. This results in an unacceptable incidence of scarring that ends up appearing in the exact shape of the tattoo while still leaving most of the tattoo behind. ${ }^{61}$ To achieve optimal results for tattoo removal, only Q-switched lasers should be used.

\section{Using Excessive Laser Energy}

Another common pitfall for laser surgeons to avoid is continually increasing laser fluence in an attempt to remove tattoo ink that has become refractory to a particular laser. To deliver higher fluences, the spot size of the laser must be diminished, thereby increasing 
the energy density. This deposits the majority of laser energy in the superficial layers of the skin, treating the epidermis and superficial dermis. The tattoo granules are generally deeper in the skin, residing in the superficial to mid dermis, and shrinking the spot size and increasing the energy may not deposit any extra energy to the tattoo granules. In fact, less laser energy may reach the tattoo granules, and the majority of laser energy serves to damage the skin and not remove the tattoo granules. What is needed in situations when a tattoo becomes refractory to a particular laser is to switch to one of the other Q-switched lasers. A particular tattoo may not be able to be completely removed by a single laser without producing a scar and in some incidences must be treated by a combination of all three types of Q-switched lasers. In this case, partial removal of a tattoo may be the best outcome for a given tattoo if all three lasers have been used, with hopes that a new technology coming down the road, such as dermal clearing agents or picosecond lasers, will remove the residual tattoo. Although it is quite expensive to own more than one Q-switched laser, laser surgeons may bundle the cases that require a second tattoo laser and bring them back on a specific day when an alternative Q-switched laser can be rented. Just as when one is trying to remove a bolt that is stuck, applying more force (fluence) will only serve to break the bolt (skin) and not achieve the desired outcome.

\section{Failing to Respect Melanin Pigment Enough}

Epidermal melanin pigment is the main competing chromophore present in the skin when treating tattoos with Q-switched lasers. Failure to lighten the skin or lower the treating fluence enough can result in temporary pigmentary alterations or even scarring. Some temporary pigment alterations, either hypopigmentation or hyperpigmentation, almost always occurs 4 to 6 weeks after laser treatment of a tattoo; however, longer-lasting pigmentary alterations can occur, especially if one does not compensate for patients with increased melanin pigment either from a tan or from genetics. When treating with the ruby or alexandrite lasers as opposed to the Nd:YAG laser, one should use relatively lower energies than one would use in lighter-skin individuals. Some dark-skinned and almost all tan patients should be treated with bleaching agents prior to the first laser treatment. I also insist that patients cover their tattoos with a bandage or clothing every time they are in the sun. If they forget to do this for a few days or simply wear sunscreen (I remind patients that the more common name for sunscreen is "suntan lotion"), I tell them to repeat the story to the laser. The laser does not care why their skin is dark, however it will "see" the skin more readily if it is tan and more easily damage it. I then send them away with bleaching agents and ask that they return in 2 to 3 weeks when the surface of the skin is lighter.

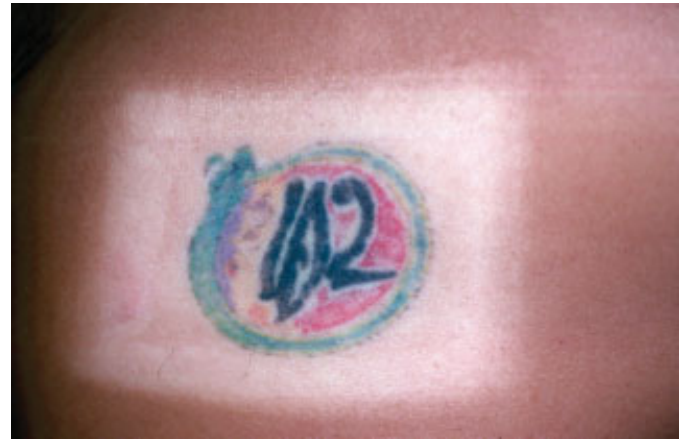

Figure 10 A patient who properly covered their tattoo with a bandage while lying in the sun in a tropical setting.

Patients who properly cover their tattoos, but who have been in the sun, are easily identifiable (Fig. 10).

\section{Allergic Reactions to Tattoo Pigments}

Patients may develop an allergy to a tattoo pigment within a given tattoo. The most common color that patients become allergic to is $\operatorname{red}^{62}$; however, red may be mixed with several other colors, such as white to make pink, and therefore may be hidden throughout a tattoo. The areas where patients are having an allergic tattoo reaction are usually raised and become nodular, scaly, and very pruritic (Fig. 11). Even though red is the most common color to elicit an allergic response from the patient, other colors may also induce an allergic response. Cadmium is often used to make yellow tattoo pigment and to brighten other colors such as red and is the most common cause of a photoallergic reaction within a tattoo. Patients with a photoallergy to yellow tattoo pigments will often give a history of pruritus when their tattoo becomes exposed to the sun and report it being elevated after sun exposure. It may be because these colors are more likely to be noticed by the immune system that red and yellow tattoo pigments often fade more quickly than other tattoo pigments in patients who are not experiencing an allergic reaction. Although colors such as red have been successfully removed in patients having an allergic reaction to these tattoo pigments, ${ }^{63,64}$ often after topical or intralesional administration of corticosteroids; I do not recommend laser treatment of these tattoos. New reports of systemic allergic reactions in patients treated with lasers for tattoos to which they are having an allergic reaction $^{65}$ (personal communication, Brian Zelickson, M.D.) suggest that physicians should observe extreme caution when considering treating such patients. Systemic allergic reactions may occur immediately after the treatment of a tattoo in a patient that is experiencing an allergic response to his or her tattoo (personal communication, Brian Zelickson, M.D.); however in at least one patient, an anaphylactic reaction occurred 1 hour after treatment of the tattoo (personal communication, Brian Zelickson, M.D.). Local and systemic reactions have also 


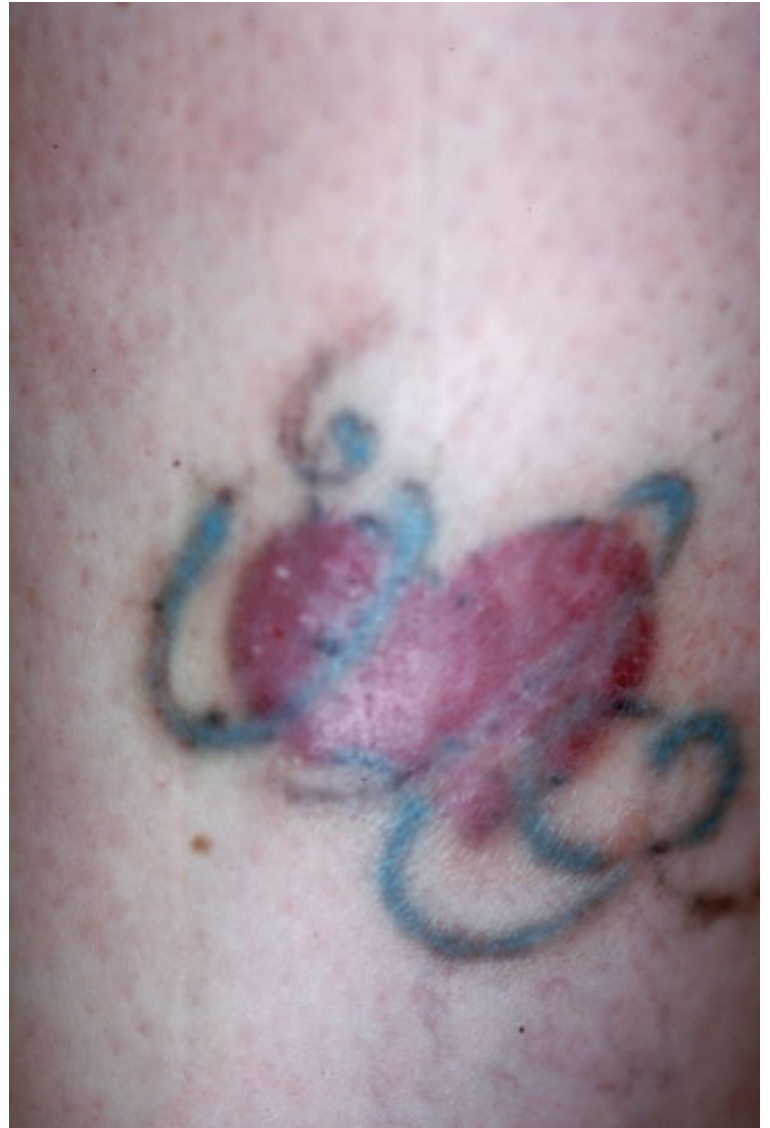

Figure 11 An allergic reaction to red tattoo pigment is evident by the raised appearance of the red pigment within this tattoo. In addition, the patients in each case reported pruritus in the red area that was treated with intralesional corticosteroids.

been reported for the first time in tattoos immediately after treatment, although these types of reactions can be delayed many days or weeks after laser treatment. ${ }^{66}$ Although some practitioners treat tattoos undergoing allergic reactions with ablative lasers such as the carbon dioxide laser, there is a report of systemic allergic reaction after $\mathrm{CO}_{2}$ laser treatment of a tattoo. ${ }^{67} \mathrm{I}$ treat tattoos undergoing an allergic reaction with topical or intralesional corticosteroids and avoid laser treatment of them altogether, offering surgical excision as the only treatment option.

\section{Darkening of Cosmetic Tattoos}

Tattoos placed as permanent cosmetics to thicken the appearance of thinning eyebrows, to camouflage scars or birthmarks, or to create an areola after surgery often contain zinc or titanium oxides. These tattoos are created to match natural skin pigments that are tan, brown, black, or red. Many of these tattoos when treated with the Q-switched lasers will turn black or gray immediately after treatment (Fig. 12). ${ }^{68-71}$ White tattoo pigment may also contain zinc or titanium oxides and can

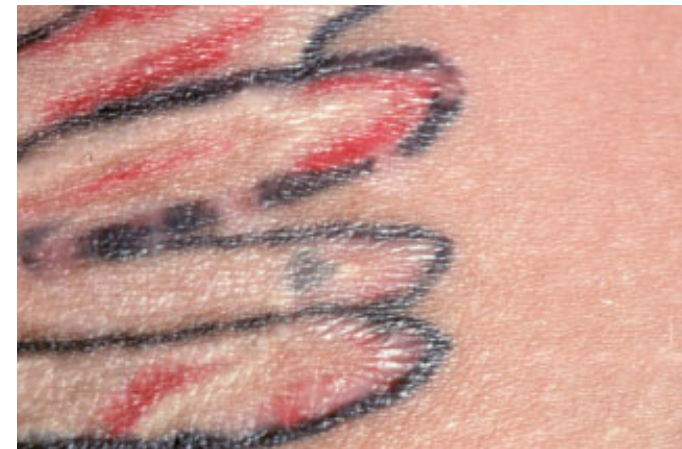

Figure 12 An unusual tattoo containing white was treated with a single test spot to determine if it would turn black or gray after treatment with the Q-switched ruby laser. The single gray spot in the center of the middle "leaf" of this strange-looking flower indicates that it will. This darkening response is usually seen immediately after laser treatment in tattoos containing zinc or titanium oxides.

turn black after treatment. It may be difficult to determine whether a tattoo contains white tattoo pigment at all or how much it contains, because white can be mixed with other colors to produce various shades. For example, red can be mixed with white to produce pink or with blue to produce light blue, and so forth. After turning gray or black, cosmetic or white tattoos can be removed by further laser treatment, ${ }^{72-74}$ but it often requires many more treatments to remove these tattoos than it does to remove a typical black tattoo. Destructive lasers have been used to remove white, tan, or brown tattoo pigments that are refractory to removal with the Qswitched lasers ${ }^{75}$; however, as with any other tattoo, $\mathrm{CO}_{2}$ laser removal will often result in scarring.

\section{Traumatic Tattoos}

A traumatic tattoo is a tattoo that is acquired as a result of some trauma where dirt, pencil graphite, ink, or even fireworks or explosives are injected into the skin as a result of the trauma. With fireworks or explosives, the particles that remain in the skin may be flammable and reignite during laser treatment. This may result in significant scarring. Tattoos resulting from explosions must be approached with great care, and a small test spot should be performed before attempting removal of large areas of these tattoos. Preferably, a skin biopsy may be analyzed to determine the nature of embedded particles before any treatment is initiated.

\section{Other Concerns}

Even though tattoo pigments are administered under the skin using a needle, there is no strict regulatory process governing or overseeing the production of tattoo inks. In addition, once in the skin, laser heating of tattoo pigments can alter their composition resulting in unknown 
by-products. ${ }^{76}$ Tattoo inks are made of several materials including heavy metals and car paints. The risk of tattoo inks turning into hazardous compounds after treatment or being hazardous out of the bottle needs to be investigated further. ${ }^{77}$ It is quite likely that regulatory agencies are going to be taking a closer look at tattoo inks in the near future. A new type of tattoo ink has been developed that encapsulates pigments that may be safer than conventional tattoo inks. Freedom-2 inks use biodegradable and bioabsorbable dyes, such as cosmeticgrade iron oxide, and encapsulate them in a biocompatible polymer bead composed of PMMA. These beads can be made with encapsulated pigment particles too small to be used as conventional tattoo inks and that would otherwise be swept away by the body due to their small size. Once encapsulated, the pigment-containing beads are the appropriate size to become trapped in the mid-dermis becoming tattoo granules. In addition, a second "target pigment" can be placed inside the beads, enabling their removal in a single laser treatment. The first placement of a Freedom-2 tattoo has been performed, and this tattoo has been removed using a single Q-switched laser treatment. Adoption of these types of encapsulated inks should revolutionize tattoo removal for the future.

\section{CONCLUSION}

Tattoos offer a unique opportunity for a laser surgeon to explore light-tissue interactions in a clinical setting. Laser-tissue interactions are most about the wavelength of the administered light and its absorption into a chromophore in the skin. Because of the wide range of colors present in modern tattoos, this interaction can be seen firsthand in a very dramatic way when removing tattoos. Tattoo removal is fun and exciting and continues to amaze me well over a decade after I first began laser tattoo removal. A large number of people acquiring tattoos in today's society ensure that tattoo removal will occupy a prominent position in the field of laser surgery. New technologies on the horizon will offer the opportunities to better and more quickly remove our patient's tattoos in the future.

\section{REFERENCES}

1. Gilbert S. Tattoo History: A Source Book. New York, NY: Juno Books; 2000

2. Allen P. Tattoo Traditions of Hawai'i. Honolulu, HI: Mutual Publishing; 2005:2-3

3. Scutt RWB, Gotch C. Art, Sex and Symbol. London, UK: Cornwall Books; 1985

4. Spindler K. The Man in the Ice: The Preserved Body of a Neolithic Man Reveals the Secrets of the Stone Age. London, UK: Weidenfeld and Nicolson; 1994:172
5. Bianchi RS. Tattoo in ancient Egypt. In: Rubin A, ed. Marks of Civilization. Los Angeles, CA: Museum of Cultural History, The University of California; 1988:26

6. Hambly WD. The History of Tattooing and its Significance. London, UK: H.F. \& G. Witherby; 1925:333

7. Rudenko SI. Frozen Tombs of Siberia: The Pazyryk Burials of Iron Age Horsemen. Berkeley, CA: The University of California Press; 1970:110-114

8. Berchon E. Histoire medicale du tatouage. Paris, France: 1869:454-455

9. Alster T, Apfelberg D. Cosmetic Laser Surgery. New York, NY: Wiley-Liss; 1996

10. Scutt RW. The chemical removal of tattoos. Br J Plast Surg 1972;25:189-194

11. Manchester GH. Removal of commercial tattoos by abrasion with table salt. Plast Reconstr Surg 1974;53:517-521

12. Johannesson A. A simplified method of focal salabrasion for removal of linear tatoos. J Dermatol Surg Oncol 1985;11: 1004-1005

13. Clabaugh W. Removal of tattoos by superficial dermabrasion. Arch Dermatol 1968;98:515-521

14. Koerber WA, Price NM. Salabrasion of tattoos. Arch Dermatol 1978;114:884-888

15. Goldman MP, Fitzpatrick RE. Cutaneous Laser Surgery: The Art and Science of Selective Photothermolysis. St. Louis, MO: Mosby-Year Book; 1994

16. Dorn B, Christophers E, Kietzman H. Treatment of portwine stains and hemangiomas by infrared contact coagulation. 17th World Congress of Dermatology Abstracts 1987; 2:307

17. Groot DW, Arlette JP, Johnston PA. Comparison of the infrared coagulator and the carbon dioxide laser in the removal of decorative tattoos. J Am Acad Dermatol 1986; 15:518-522

18. Colver GB, Cherry GW, Dawber RP, Ryan TJ. Tattoo removal using infrared coagulation. Br J Dermatol 1985;112:481-485

19. Venning VA, Clover GB, Millard PR, Ryan TJ. Tattoo removal using infrared coagulation: a dose comparison. $\mathrm{Br}$ J Dermatol 1987;117:99-105

20. Gupta SC. An investigation into a method for the removal of dermal tattoos: a report on animal and clinical studies. Plast Reconstr Surg 1965;36:354-361

21. Ruiz-Esparza J, Goldman MP, Fitzpatrick RE. Tattoo removal with minimal scarring: the chemo-laser technique. J Dermatol Surg Oncol 1988;14:1372-1376

22. Dvir E, Hirshowitz B. Tattoo removal by cryosurgery. Plast Reconstr Surg 1980;66:373-379

23. Colver GB, Dawber RP. The removal of digital tattoos. Int J Dermatol 1985;24:567-568

24. Buncke HJ Jr, Conway H. Surgery of decorative and traumatic tattoos. Plast Reconst Surg 1957;20:67-77

25. Bailey BN. Treatment of tattoos. Plast Reconstr Surg 1967; 40:361-371

26. Fujimori Y. Treatment of nevus of Ota and nevus spilus. In: Skin Surface Surgery. Tokyo, Japan: Kokuseido Publishing Co.; 1990:181-188

27. Kobayashi T. Microsurgical treatment of nevus of Ota. J Dermatol Surg Oncol 1991;17:936-941

28. Cosman B, Apfelberg DB, Druker D. An effective cosmetic treatment for Ota's nevus. Ann Plast Surg 1989;22:36-42

29. Goldstein N, Penoff J, Price N, et al. Techniques of removal of tattoos. J Dermatol Surg Oncol 1979;5:901-910

30. Morgan BD. Tattoos. BMJ 1974;3:34-36 
31. Gupta SC. An investigation into a method for the removal of dermal tattoos: a report on animal and clinical studies. Plast Reconstr Surg 1965;36:354-361

32. Apfelberg DB, Maser MR, Lash H. Argon laser treatment of decorative tattoos. Br J Plast Surg 1979;32:141-144

33. Maser MR, Apfelberg DB, Lash H. Clinical applications of the argon and carbon dioxide lasers in dermatology and plastic surgery. World J Surg 1983;7:684-691

34. McBurney EI. Carbon dioxide laser treatment of dermatologic lesions. South Med J 1978;71:795-797

35. Brady SC, Blokmanis A, Jewett L. Tattoo removal with the carbon dioxide laser. Ann Plast Surg 1979;2:482-490

36. Bailin PL, Ratz JR, Levine HL. Removal of tattoos by $\mathrm{CO}_{2}$ laser. J Dermatol Surg Oncol 1980;6:997-1001

37. Reid R, Muller S. Tattoo removal by $\mathrm{CO} 2$ laser dermabrasion. Plast Reconstr Surg 1980;65:717-721

38. Fitzpatrick RE, Ruiz-Esparza JN, Goldman MP. The depth of thermal necrosis using the $\mathrm{CO} 2$ laser: A comparison of the superpulsed mode and conventional modes. J Dermatol Surg Oncol 1991;17:340-344

39. Ruiz-Esparza J, Goldman MP, Fitzpatrick RE. Tattoo removal with minimal scarring: The chemo-laser technique. J Dermatol Surg Oncol 1988;14:1372-1376

40. Apfelberg DB, Maser MR, Lash H, White DN, Flores JT. Comparison of the argon and carbon dioxide laser treatment of decorative tattoos: a preliminary report. Ann Plast Surg 1985;14:6-15

41. Apfelberg DB, Maser MR, Lash H, Rivers J. The argon laser for cutaneous lesions. JAMA 1981;245:2073-2076

42. Ohshiro T, Maruyama Y. The ruby and argon lasers in the treatment of naevi. Ann Acad Med Singapore 1983;12:388391

43. Trelles MA, Verkruysse W, Pickering JW, et al. Monoline argon laser $(514 \mathrm{~nm})$ treatment of benign pigmented lesions with long pulse lengths. J Photochem Photobiol B 1992; 16:357-360

44. Bernstein EF, Kornbluth S, Brown DB, Black J. Treatment of spider veins using a 10 millisecond pulse-duration frequency-doubled neodymium YAG laser. J Dermatol Surg 1999;25:316-320

45. Goldman L, Blaney DJ, Kindel DJ Jr, Richfield D, Franke EK. Pathology of the effect of the laser beam on the skin. Nature 1963;197:912-914

46. Goldman L, Wilson RG, Hornby P, Meyer RG. Radiation from a $\mathrm{Q}$-switched ruby laser. Effect of repeated impacts of power output of 10 megawatts on a tattoo of man. J Invest Dermatol 1965;44:69-71

47. Anderson RR, Parrish JA. Selective photothermolysis: Precise microsurgery by selective absorption of pulsed radiation. Science 1983;220:524-527

48. Taylor CR, Gange RW, Dover JS, et al. Treatment of tattoos by $\mathrm{Q}$-switched ruby laser. A dose-response study. Arch Dermatol 1990;126:893-899

49. Scheibner A, Kenny G, White W, Wheeland RG. A superior method of tattoo removal using the Q-switched ruby laser. J Dermatol Surg Oncol 1990;16:1091-1098

50. Ashinoff R, Geronemus RG. Rapid response of traumatic and medical tattoos to treatment with the $\mathrm{Q}$-switched ruby laser. Plast Reconstr Surg 1993;91:841-845

51. Kilmer SL, Anderson RR. Clinical use of the Q-switched ruby and the Q-switched Nd:YAG (1064 nm and $532 \mathrm{~nm}$ ) lasers for treatment of tattoos. J Dermatol Surg Oncol 1993; 19:330-338
52. Kilmer SL, Lee MS, Grevelink JM, Flotte TJ, Anderson RR. The Q-switched Nd:YAG laser effectively treats tattoos. A controlled, dose-response study. Arch Dermatol 1993;129: 971-978

53. Jones A, Roddey P, Orengo I, Rosen T. The Q-switched ND:YAG laser effectively treats tattoos in darkly pigmented skin. Dermatol Surg 1996;22:999-1001

54. Fitzpatrick RE, Goldman MP. Tattoo removal using the alexandrite laser. Arch Dermatol 1994;130:15081514

55. Alster TS. Q-switched alexandrite laser treatment $(755 \mathrm{~nm})$ of professional and amateur tattoos. J Am Acad Dermatol 1995;33:69-73

56. Leuenberger ML, Mulas MW, Hata TR, Goldman MP, Fitzpatrick RE, Grevelink JM. Comparison of the Q-switched alexandrite, $\mathrm{Nd}: Y A G$, and ruby lasers in treating blue-black tattoos. Dermatol Surg 1999;25:10-14

57. Zelickson BD, Mehregan DA, Zarrin AA, et al. Clinical, histologic, and ultrastructural evaluation of tattoos treated with three laser systems. Lasers Surg Med 1994;15:364372

58. Ross V, Naseef G, Lin G, et al. Comparison of responses of tattoos to picosecond and nanosecond Q-switched neodymium: YAG lasers. Arch Dermatol 1998;134:167171

59. McNichols RJ, Fox MA, Gowda A, Tuya S, Bell B, Motamedi M. Temporary dermal scatter reduction: quantitative assessment and implications for improved laser tattoo removal. Lasers Surg Med 2005;36:289-296

60. Bhardwaj SS, Brodell RT, Taylor JS. Red tattoo reactions. Contact Dermatitis 2003;48:236-237

61. Antony FC, Harland CC. Red ink tattoo reactions: successful treatment with the Q-switched $532 \mathrm{~nm} \mathrm{Nd:YAG} \mathrm{laser.} \mathrm{Br} \mathrm{J}$ Dermatol 2003;149:94-98

62. Dave R, Mahaffey PJ. Successful treatment of an allergic reaction in a red tattoo with the Nd-YAG laser. Br J Plast Surg 2002;55:456

63. Kuperman-Beade M, Levine VJ, Ashinoff R. Laser removal of tattoos. Am J Clin Dermatol 2001;2:21-25

64. England RW, Vogel P, Hagan L. Immediate cutaneous hypersensitivity after treatment of tattoo with $\mathrm{Nd}: Y A G$ laser: a case report and review of the literature. Ann Allergy Asthma Immunol 2002;89:215-217

65. Zemtsov A, Wilson L. CO2 laser treatment causes local tattoo allergic reaction to become generalized. Acta Derm Venereol 1997;77:497

66. Anderson RR, Geronemus R, Kilmer SL, Farinelli W, Fitzpatrick RE. Cosmetic tattoo ink darkening. A complication of Q-switched and pulsed-laser treatment. Arch Dermatol 1993;129:1010-1014

67. Jimenez G, Weiss E, Spencer JM. Multiple color changes following laser therapy of cosmetic tattoos. Dermatol Surg 2002;28:177-179

68. Chang SE, Kim KJ, Choi JH, Sung KJ, Moon KC, Koh JK. Areolar cosmetic tattoo ink darkening: a complication of Q-switched alexandrite laser treatment. Dermatol Surg 2002; 28:95-96

69. Ross EV, Yashar S, Michaud N, et al. Tattoo darkening and nonresponse after laser treatment: a possible role for titanium dioxide. Arch Dermatol 2001;137:33-37

70. Rudlinger R. Successful removal by ruby laser of darkened ink after ruby laser treatment of mismatched tattoos for acne scars. J Cutan Laser Ther 2000;2:37-39 
71. Moreno-Arias GA, Camps-Fresneda A. The use of Q-switched alexandrite laser (755 nm, $100 \mathrm{~ns})$ for eyeliner tattoo removal. J Cutan Laser Ther 1999;1:113-115

72. Fitzpatrick RE, Lupton JR. Successful treatment of treatmentresistant laser-induced pigment darkening of a cosmetic tattoo. Lasers Surg Med 2000;27:358-361

73. Herbich GJ. Ultrapulse carbon dioxide laser treatment of an iron oxide flesh-colored tattoo. Dermatol Surg 1997;23:60-61

74. Baumler W, Eibler ET, Hohenleutner U, Sens B, Sauer J, Landthaler M. Q-switch laser and tattoo pigments: first results of the chemical and photophysical analysis of 41 compounds. Lasers Surg Med 2000;26:13-21
75. Vasold R, Naarmann N, Ulrich H, et al. Tattoo pigments are cleaved by laser light-the chemical analysis in vitro provide evidence for hazardous compounds. Photochem Photobiol 2004;80:185-190

76. Baumler W, Eibler ET, Hohenleutner U, Sens B, Sauer J, Landthaler M. Q-switch laser and tattoo pigments: first results of the chemical and photophysical analysis of 41 compounds. Lasers Surg Med 2000;26:13-21

77. Vasold R, Naarmann N, Ulrich H, et al. Tattoo pigments are cleaved by laser light-the chemical analysis in vitro provide evidence for hazardous compounds. Photochem Photobiol 2004;80:185-190 